\title{
The Leprosy Problem in British Guiana.
}

F. G. Rose.

B RITISH GUIANA, the only British possession on the South American mainland, has never been slow either to adopt or to enforce measures for the treatment or eradication of leprosy. The Mahaica Leprosy Hospital, whose buildings stand on grounds over sixty acres in extent, was established in 1858, the well-known leprologist, Hillis, being its first Medical Superintendent, and here Professor Deycke worked in 1910. Compulsory isolation was adopted as early as 1905, conditional discharges in 1911 ; at the present time the proportion of cases rendered negative and conditionally discharged bears comparison with that of any other settlement in the world. Every modern line of treatment has been or is being explored, and is available for those who wish to take advantage of it.

In British Guiana leprosy was not always endemic. To this day, by all accounts, it is unknown among the true aborigines, the Indian tribes of the interior. Introduced by the African slave traffic and fed by indentured immigration from India, after more than a century it shows no startling increase, though it must be admitted that it holds its own. Never was there such an opportunity as is now placed before this country completely to eradicate the disease. But the great obstacle to anti-leprosy work here lies in the psychology of the inhabitants. The East Indian seems to regard leprosy with a species of quiet fatalism ; it inspires in him no special abhorrence. Not so the others ; they are still haunted by the spectre of the decrepit victims of advanced leprosy who once formed the bulk of the inhabitants of the Hospital. The diagnosis of leprosy is to them as a sentence of death, Rumour, fiction, training, biblical tradition, all unite to inspire an indescribable horror of the disease. The priest from the pulpit compares leprosy to mortal sin. It is said 
that one member of the Legislative body holds his breath as he motors by ; many people would sacrifice a large sum rather than pay even a casual visit to this hospital. Indeed, in the past the chief source of information as to the existence of cases of leprosy has consisted in anomymous letters, inspired by dread or malice or a mixture of 'both, addressed to the Medical Superintendent of the Leprosy Hospital, the Medical Officer of Health, the Surgeon-General, or the Police. To these people the word leprosy conjures up a hapless, helpless, mutilated cripple, "sans teeth, sans eyes, sans taste, sans everything."

It is against this well-nigh immovable bedrock of prejudice that it is necessary to fight. Such an attitude obstructs leprosy work in two ways. In the first place it interferes with the discovery of early cases, which is so important, for it leads to concealment till concealment is no longer possible, which is to say, till effective treatment becomes more difficult. Secondly, it restricts the opportunities of employment of discharged cases.

While in India, in 1928, I asked the Superintendent of the Purulia Leprosy Settlement if he experienced this difficulty. He explained that the patients were drawn from so large an area that the employer was seldom aware that the patient had had treatment at a leprosy centre.

Here, where the population is smaller, and the tendency is to consider everyone else's business as one's own, it would be very difficult to keep such knowledge from interested parties. So irrational is the prejudice, moreover, that, paradoxical as it may seem, a sufferer who has never been to the Leprosy Hospital inspires less terror than one who has been an inmate, and thus presumably received thorough treatment.

Notwithstanding, do not think that I am asserting that the position is not improving. Slowly but surely the knowledge is permeating the general population that the disease is not incurable, that it is, in fact, when taken early, one of the most amenable diseases to treatment. There is moreover in British Guiana a form of local patriotism which, if skilfully exploited, is a valuable asset. To illustrate this, some time ago, in doing leprosy survey work, I found a portion of the colony, long regarding itself with legitimate pride as a kind of health-resort, heavily infected with leprosy. A medical colleague, aware of the sentiments of the inhabitants, assured me that it would be dangerous for me to revisit this district owing to the resentment aroused by the publication of this information. On the contrary, however, as I anticipated, 
every single sufferer seen by me on that survey is under treatment, and every infectious case isolated, and so far from resentment having been aroused, there now exists a very healthy determination to rid the district of the reproach of so high a leprosy index.

Particularly effective propaganda is the discharge of cases without stigmata of leprosy, able to earn their own living in the outside world. I estimate that in the districts visited by me in the course of my survey work, over 90 per cent. of the cases are now known, and under treatment.

From May, 1926, when I was appointed Medical Superintendent of this hospital, to November, 1930, 166 persons have been discharged, and it must be borne in mind that well over 90 per cent. of the cases now discharged are persons sound in wind and limb, as against a percentage of about thirty under previous conditions. Of this number, twenty, that is 12.4 per cent., have had a recurrence of symptoms. Wade and Lara, from the Culion Island Settlement, have, however, pointed out that in many of these cases one is dealing not with true relapses, but with an "interruption," an inevitable stage in the progress to a permanent negative. Thus considered, six of these cases, in which symptoms recurred within six months, cannot be considered as true relapses, thus reducing the number to fourteen, or 8.7 per cent. Of the twenty, eleven became negative again shortly after, and have remained so, one remains negative, but has lost his sight from corneal ulceration, one has died from intercurrent disease, while the remaining seven have $: m$ proved considerably, but not yet to such a degree as to make it possible to discharge them afresh.

Another aspect of the leprosy problem concerns itself with the early negative case, not requiring isolation, but regular and vigorous treatment. One finds that it is not difficult to induce patients discharged as negative to attend the hospital periodically for examination and treatment. With those who have never experienced the restrictions of life in a settlement, the case is, however, entirely different. The slow progress of the disease, the inconvenience, not to say impossibility at times of leaving their work to attend at a centre over twenty miles distant, where the difficulties of transportation involve the loss of a full day's work, conspire to make them irregular in attendance and difficult to persuade that it is necessary to undergo so lengthy a course of treatment. Unfortunately, the present financial condition of the colony puts the establishment of district out-patient clinics beyond the reach of the authorities, 
and makes it necessary either to persuade these cases to come into the leprosy hospital or to leave them entirely without treatment."

No opportunity for propaganda is lost. Magic-lantern lectures have proved very popular, and have been the means of inducing many cases to present themselves voluntarily for treatment. Indeed, one can point with pride to the fact that, for the first time in the history of this hospital, the majority of those admitted have been so admitted at their own request, while in four and a half years only one person has been tempted to abscond.

Moreover, whereas in 1927 only 57.9 per cent. of the inmates were able-bodied, capable of fending for themselves without assistance, at the present time $66^{\circ} 4$ per cent. are in that happy condition, in spite of the fact that over 100 ablebodied persons have been discharged as negative.

To conclude, the position of the leprosy campaign in British Guiana at present stands thus :-

With 288 in the Leprosy Hospital, about 250 discharged conditionally and living outside, there are probably over 600 cases of leprosy in a population of 300,000 , representing an index of two per mille. There is urgent need of more survey work to serve the purpose, both of ascertaining the true extent of infection and of inducing suspects to come forward for examination and treatment.

No less urgent is the need of out-patient clinics to supply the wants of those who are not required to be isolated for the protection of the public health.

A new Leprosy Ordinance, which is a great advance on the one now in force, is about to be introduced before the Legislative Council, and it is hoped that, with assistance from the British Empire Leprosy Relief Association, all the measures indicated above will be in force in the coming year.

If this proves to be the case, I am confident that it will not be many years before we shall be able to show, like Norway, statistics demonstrating the gradual decline of leprosy in British Guiana.

-The Association has just given a grant of $\mathbf{E 0 0}$ for the purpose of further ourvey work and the establjohment of clinics.-Editor. 